\title{
'Emergency' ban on 2,4,5-T herbicide in US
}

Clive Cookson reports from Washington on swift reaction to a study linking 2,4,5-T with an increase in miscarriages

THE US Environmental Protection Agency has taken emergency action to ban the use of the controversial herbicide $2,4,5-\mathrm{T}$, after receiving new evidence linking it to a high incidence of miscarriages in Oregon.

"Studies completed only days ago show a high miscarriage rate immediately following the spraying of 2,4,5-T in the forests around Alsea, Oregon," explained EPA deputy administrator Barbara Blum. "This alarming correlation comes at a time when seven million pounds of 2,4,5-T are about to be used to control weeds on power line rights-of-way and in pastures, and to manage forests across the nation".

These uses will be stopped ummediately by "emergency suspension" -the most drastic action EPA can take against a herbicide or pesticide, and the first time it has ever been invoked. The closely related herbicide, Silvex, which is used primarily to kill weeds on suburban lawns, is also covered by the order. But the remaining legal uses of $2,4,5-\mathrm{T}$, on open ranges and rice fields, are not included and may continue, the EPA said, "because they appear at this time not to involve human exposure comparable to the suspended uses".
However, the Environmental Defense Fund has rejected this argument and petitioned EPA for a total ban on all uses.

2,4,5-T [2,4,5-trichlorophenoxyacetic acid] and Silvex [2-(2,4,5-trichlorophenoxy)propionic acid] are both contaminated with small amounts of 'dioxin' (TCDD), which produces birth defects, miscarriages and tumours in animals, even at extremely low concentrations. The dioxin is thought to be responsible for their ill effects on animals.

For eight years, US environmentalists have been fighting legal and administrative battles against the continued use of 2,4,5-T (which was applied as a military defoliant in Vietnam and was widely blamed for the high incidence of birth defects there). But the EPA claims that its latest study is the first to link the herbicide clearly to ill effect on humans.

The agency commissioned the study last year when nine women from Alsea wrote to say they had had miscarriages after the national forest there was sprayed with 2,4,5-T. Scientists from Colorado State University and the University of Miami medical school compared miscarriages in the Alsea basin (western Oregon) with a control population in rural eastern Oregon. They reported that:

- The miscarriage rate in the Alsea area was significantly higher than in the control area, where $2,4,5$ - $\mathrm{T}$ was not sprayed.

- The rate peaked dramatically in June in each of the six years studied, two or three months after the annual spring spraying. The spontaneous abortion index in June over the period 1972-77 was 130 per 1,000 births in Alsea and 46 per 1,000 in the control area.

Dr Blum said: "It's a remarkable correlation. While it is not proof of a cause and effect relationship, it is highly suggestive, particularly in light of animal data, and gives great cause for concern". She estimated that four million people across the United States would be protected by the emergency action.

The EPA claims that the short-term economic impact of the ban will be slight, because alternative herbicides are available for use on pasture and rights-of-way, and only $0.2 \%$ of the country's commercial forest area is sprayed annually. The long-term cost to forestry of a permanent ban could be $\$ 7 \mathrm{~m}-12 \mathrm{~m}$ a year, because other herbicides are less effective and more expensive.

Dow Chemical is the leading manufacturer of 2,4,5-T and Silvex. A few
Dioxin: the 10-year battle that began with Agent Orange

\author{
Alastair Hay traces the steps \\ leading up to the EPA ban
}

EVER since the late 1960 s when the herbicide 2,4,5-T was found to contain the extremely toxic contaminant 2,3,7,8-tetrachlorodibenzodioxin (dioxin), there has been much concern over its continued use. It has already been banned in some European countries.

According to $\mathrm{Mr}$ Frank Parsons of the EPA's Pesticide Programme, $2,4,5-\mathrm{T}$ is the biggest single issue the agency has had to deal with so far. In April last year, the agency issued its "Rebuttable Presumption against Registration and continued Registration of Pesticide Products containing 2,4,5-T", and interested parties were given 45 days in which to submit evidence supporting or opposing the use. An additional 60 days grace was granted following a request from one of the major manufacturers for more time to present its case.

Parsons says that the EPA has received over 2,700 submissions on 2,4,5-T ranging from a 2,300-page memorandum from Dow Chemicalthe major manufacturer of $2,4,5-\mathrm{T}$ - supporting its use, to individuals claiming they were sprayed with the herbicide and their "hair dropped out". Asked how seriously the agency considered such comments, Parsons said that if enough of these claims are made "we can't ignore them." But the main protagonists in the debate are the chemical manufacturers and environmental pressure groups.

During the Vietnam war, Dow supplied most of the 2,4,5-T used by US forces in their defoliation programmes in Vietnam. It was used at that time in a $1: 1$ combination with 2,4 dichlorophenoxyacetic acid, called Agent Orange.

In 1969, Agent Orange was reported to be teratogenic (causing foetal abnormalities) in a study published by the US Bionetics Research Laboratory. Although it was subsequently shown that it was the dioxin con- taminant-sometimes present in quantities in excess of $30 \mathrm{ppm}$-which was teratogenic and not $2,4,5,-\mathrm{T}$ itself, the Bionetics study led the US Government to withdraw Agent Orange from Vietnam and to restrict 2,4,5-T use in the US to forestry and clearing rights of way.

It was the high dioxin contamination which marked $2,4,5-\mathrm{T}$ as a teratogen. The EPA reasoned, therefore, that reducing this contamination to less than $0.1 \mathrm{ppm}$ might render it safe. However, as more evidence about dioxin's toxicity accrued, the agency was forced to review the situation. In 1972 , Dow obtained a temporary court injunction preventing EPA from taking further action against $2,4,5-\mathrm{T}$. The following year, this was overturned by the US Count of Appeal. When the first hearings were held by the EPA in 1974 they proved inconclusive: there was insufficient data supporting allegations that dioxin in $2,4,5-\mathrm{T}$ presented a health risk, and an order proposing the cancellation of $2,4,5-\mathrm{T}$ was withdrawn.

The latest evaluation of the herbicide has thus been a continuation of 
other firms also make them. Although the emergency suspension took effect from the moment it was announced on 1 March, the companies can appeal to have it lifted. When the suspension issue is settled, "cancellation hearings" will begin, to determine whether the herbicides should be banned permanently. That will take years to decide.

\section{EPA disputes Dow claim}

The Environment Protection Agency has disputed claims by Dow Chemical that some dioxin compounds found in the environment are the result of normal combustion processes. The claim was made by the chemical company last November as part of its defence against charges that pollution associated with its herbicide production plant at Midland in Michigan was resulting in trace elements in fish in the Tittabawassee River.

Dow claimed that, since it had found dioxins associated with a number of combustion sources including car exhaust and charcoal grills, dioxins were formed by normal combustion processes. But EPA says this claim was based on purely circumstantial evidence. It points out that evidence submitted by Dow to the EPA shows dioxin levels two to four times higher in Midland than in other locations checked. It also criticises Dow for using analytical techniques and procedures which have not yet been corroborated by other scientists.

the earlier reviews, but with the difference that all sides have been claiming sufficient evidence to support their case. Mr Gary Jones, a spokesman for Dow Chemical told Nature in an interview before the EPA ban was announced that the company's view was that "if, with all the confidence we have on the safety of $2,4,5-\mathrm{T}$, we can't say it is safe, then we can't prove the safety of aspirin".

The company felt that the attack on 2,4,5-T is part of a campaign by environmental groups whose campaign will not stop with the banning of the herbicide. Dow sees itself as defending an attack on the chemical industry by environmentalists who, Jones said, "want to go back to windmills". Jones added that Dow was defending 2,4,5- $\mathrm{T}$ not because the herbicide is a large revenue earner-sales worth $\$ 12 \mathrm{~m}$ represent only about $0.2 \%$ of the company's total annual incomebut because it is "science which should be determining 2,4,5-T safety, not emotion".

The basis of Dow's argument is that dioxin at $0.1 \mathrm{ppm}$ in $2,4,5-\mathrm{T}$ presents no human health hazard. The company has been defending this

\section{Dow admits 'poor' lab results}

THE US Environmental Protection Agency (EPA) has not only been reviewing the safety of the herbicide $2,4,5-\mathrm{T}$; it is also engaged in a major collaborative programme with US scientists to compare laboratory measurements of 2,3,7,8-tetrachlorodibenzodioxin (dioxin) - a toxic contaminant present in the herbicide.

Central to the EPA's concern about dioxin is the poor reproducibility of dioxin measurements. In an attempt to find out which laboratories were reliable the EPA induced five labs to take part in a collaborative programme. The results of this collaboration were reviewed at a recent meeting in Washington organised by the agency.

The potential threat posed by $2,4,5-T$ is that its dioxin contaminant will enter the human food chain. US scientists claimed recently that dioxin had been detected in beef fat and human milk. The same two vehicles were therefore chosen by the EPA for its programme. Fat and milk samples were 'spiked' with dioxin in quantities ranging from $0-8 \mathrm{ppt}$ (parts in $10^{12}$ ) and extracts prepared suitable for analysis. The extracted samples, together with known standards-all prepared by the EPA Pesticide Monitoring Laboratory at Bay St Louis, Mississippi-were randomised and sent to the five participants: the Dow Chemical Company; Harvard University; the University of

claim not only before the EPA but also in a New York federal court. Dow and five other US manufacturers of $2,4,5-\mathrm{T}$ are being sued for $\$ 10 \mathrm{~m}$ by the estate of a 28-year-old Vietnam veteran, Paul Reutershan, who died in December last year of terminal cancer of the colon.

Reutershan, a helicopter crew chief in the Vietnam war, flew on several herbicide spraying missions during which Agent Orange was used. Ten years later when he was diagnosed as having cancer, Reutershan was convinced that dioxin was the cause. Following his death, a new suit was brought on his behalf as well as on that of "all American servicemen whose health has been damaged, or is likely to be damaged, because of contact with Agent Orange". The new suit has been filed by a veteran attorney of chemical contamination cases, Victor Yannacome Jnr, and is likely to prove a test case.

There is little comfort for the litigants, however, from the Veterans Administration (VA). The VA has reviewed some 500 claims from exservicemen-mainly from the Chicago area-that exposure to $2,4,5-\mathrm{T}$ has
Nebraska; Wright State University, Ohio; and the EPA Health Effects Research Laboratory (HERL) in North Carolina.

If proof were needed that there is inter-laboratory variation, then this study provided it. Only two laboratories performed well in the study-those of Dr Michael Gross of Nebraska and Dr Matthew Meselson of Harvard. The EPA's own laboratory results were regarded as reasonable by scientists present at the meeting but those of the other two were felt to be poor-Dow's being the less accurate.

The fact that Dow Chemical performed badly in this collaborative programme has not passed unnoticed by some scientists in the field. They argue that it should have been Dow, a company with a long-standing interest in dioxin measurements, which came out at the top of this league table. Dr Warren Crummett, of Dow, confessed that his results were "poor". "They were worse than normal", he told Nature. According to Crummett, some of the blame lies with the method of dioxin extraction chosen by the EPA. Had Dow done its own extracting procedure, then, Crummett was convinced, his laboratory's results would have been much better.

Of the five laboratories, only Gross's performed well in identifying 'false positives' and 'false negatives'. Discon-

damaged their health. But, a spokesman said, the administration has not been able to prove that "any of these claims are herbicide-related".

Environmental groups such as the Environmental Defense Fund insist that the very presence of dioxin renders the use of $2,4,5-\mathrm{T}$ dangerous. For these groups the fact that dioxin has been shown in three separate studies to be a carcinogen, and that it is always present as a contaminant in 2,4,5T-albeit at a low concentration-is sufficient to proscribe its use in any circumstances.

Balancing these conflicting arguments was apparently a difficult exercise for the EPA. Before the ban was announced, the Agency admitted that it was practically impossible to do a "precise reckoning" of the risks and benefits of the herbicide. One official of the Agency confessed that the "political climate is terrific on this issue" and that it did complicate matters. However, as he saw it, the EPA's role was to review the evidence and if the Agency made both the environmentalists and industry unhappy then "we are probably doing our job". 